\title{
What is the Status of Omani Parents on their Children's Healthy Lifestyle?
}

\author{
Hashem A. Kilani* \\ \& Ibrahim A. Al-Qaryouti \\ University of Jordan, Amman, Jordan \\ Sultan Qaboos University, Sultanate of Oman \\ Received: 28/7/2016 \\ Accepted: 30/8/2016
}

\begin{abstract}
The purpose of this study was to document the significance of the practices employed by parents that contribute to children's healthy lifestyle in Oman. Those practices encompassed the physical activity and inactivity, sedentary behaviour, nutritional knowledge, and its reflection on their children at early childhood class. Subjects consisted of 237 male and female parents of kindergarten children in the Sultanate of Oman. The researchers developed a twenty-three and a twenty-item questionnaire intended to measure the degree of parent involvement in their children's impact at acceptable levels of validity and reliability. (Amazingly, it was found that parents' healthy lifestyle were low in their habit practices (low in engagement to physical activity, sports and daily life activity) which showed a trend of sedentary lifestyle. Meanwhile, they did not encourage their children to participate in physical activity nor control them from staying away from being in front of TV screen and video games, too. In addition, their nutritional knowledge also scored low which affected their children's health negatively. It is, therefore, suggested that lifestyle concept should be inculcated in the learning process for children, and further analysis be made as to what extent the demographic category may influence parents' involvement towards their children's healthy lifestyle.
\end{abstract}

Keywords: Lifestyles, parents, Oman, childhood.
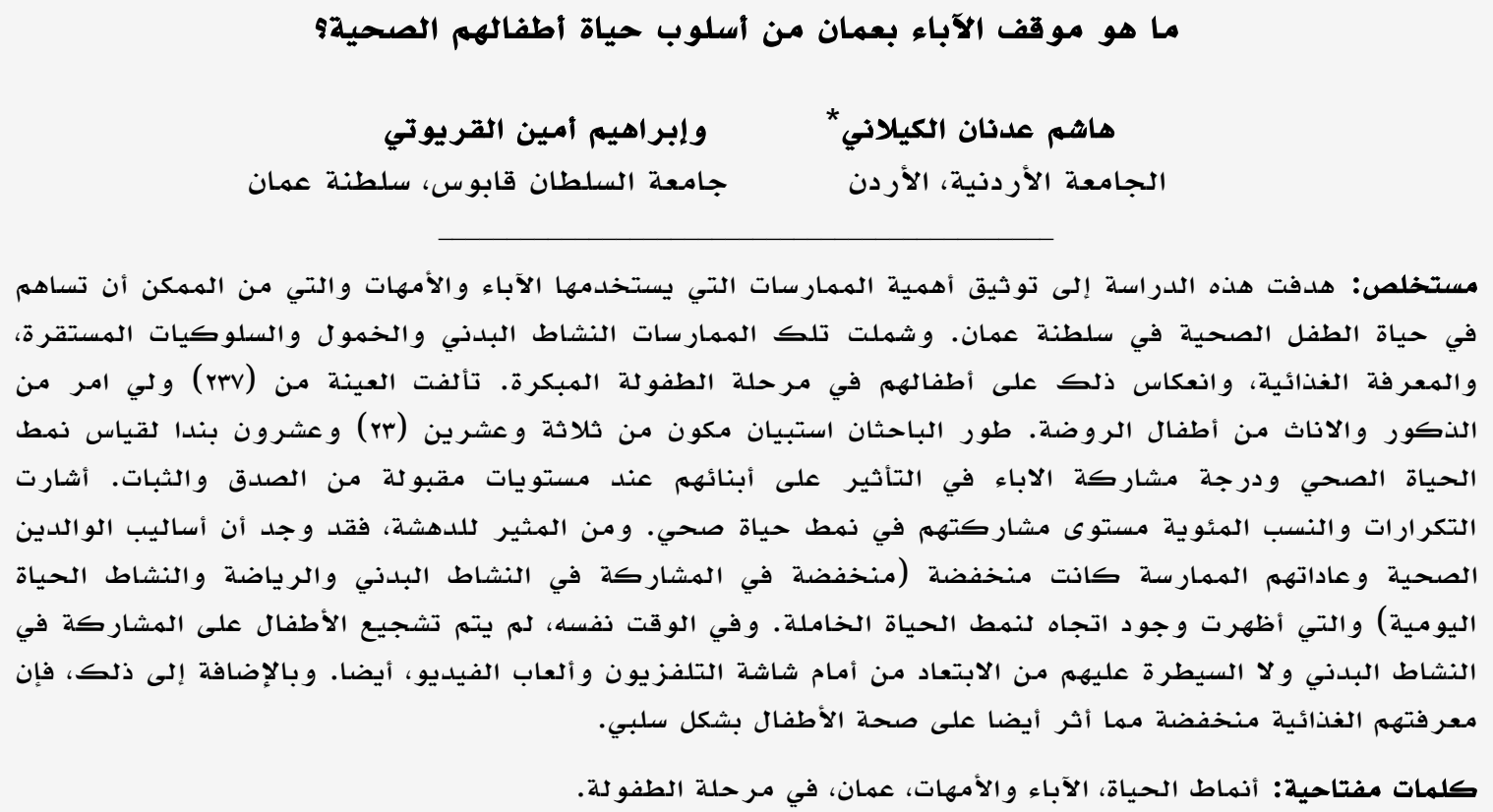

*hashemkilani@gmail.com 
Lifestyle is the typical way of life of an individual, group, or culture (the way we live). The more time spent on hygiene, physical fitness, and diet regulation, the healthier lifestyle is. Lifestyle behavior may contribute to unhealthy risk factors (modifiable vs. stable). It was known that lifestyle factors including intellectual involvement, reduced smoking tobacco, sleep curtailment, stresses, nutrition selection, social communication, and physical activity contribute a lot on health improvement.

Adult lifestyle factors particularly obese parents mediated the effects of family living arrangements in childhood. Although we are naturally wired to hear and learn to speak, we are not pre-programmed for lifestyle behaviours. Humans must learn the skills and practice them, so that is how we become literat. (Al-Qaryouti \& Kilani, 2015). Emergent literacy is a gradual process that takes place over time from birth until a child learns to read and write with many lifestyles behaviours.

In a study on standardized tests, students in the best physical shape outscore their classmates and take home better grades. Besides, higher grades were associated with vigorous physical activity, particularly activity meeting recommended healthy people 2010 levels (American Heart Association, 2010). Level of fitness and achievement are associated positively in Jordan (Kilani \& Alerjan, 2001). Meanwhile, Brophy, Rees, Knox, Baker, \& Thomas (2012) concluded that interventions need to focus on mothers' lifestyle in pregnancy, fathers' health, as well as promoting fitness among children.

Nonetheless, children who are physically active at least for an hour per day are healthier, calmer, less violent and better in their education, as one hour of physical activity reduces the risk of obesity by 10\%. (Kilani, Alhazzaa, Waly, \& Musaiger, 2013) Rising screen time (watching TV and movies, playing electronic games, using mobile phones and computers or web surfing) is not helping. When children's screen time increased, their level of physical activity dropped significantly, and their body mass indices rose significantly. (Lindsay, Sussner, Kim \& Gortmaker, 2006). Evidence for the effectiveness of parental components on children's health behaviours were also inconsistent suggesting that parents should be directly involved from the earliest stages of child development to support healthful practices both inside and outside of home (VanLippevelde, Verloigne, Bourdeaudhuij, Brug, Bjelland, Lien, and Maes, 2012).

As exercise and physical activity consist of a friendly positive direction for physical activity, later in life and thus is in any case much healthier person (Mehana \& Kilani, 2010). Today's children may fantasize about growing up to be graceful superstars, athletes or models. The irony, however, is that children are, in large measure, inactive, unfit and increasingly overstressed by their teachers and parents.

Parents who are more physically active will have livelier, healthy kids. Parents can play a major role in encouraging children to become more active even though, their child is obese. Obesity arises from a genetic tendency. This is the case for children who have at least one parent who is obese. On the other hand, obesity comes from environmental factors leading the child to become obese (Kilani, 2014).

Children are bound to pick up on their parents' feeding habits. If parents eat more fruits and vegetables every day, then so their child ends up matching them. If parents eat too much fast food, then their child will end up doing the same. Being aware of the parental contribution to childhood overweight will empower parents to define a nutritional regimen that will keep the child's weight within healthy limits. Parents can support their children's physical activity via both direct and indirect reinforcement. Parents who support physical activity tend to have children who are more physically active than children whose parents do not display these types of behaviours (Welk, Wood, \& Morss, 2003). In order to lead healthier lifestyles, improving knowledge and skills of children and parents; increasing motivation through parental empowerment and role modelingmust be adopted.

The Leisure and Cultural Services Department (LCSD, 2013) recently released the findings of a city-wide community fitness test and survey that involved more than 8,100 people, of whom about $70 \%$ were children aged 3 to 19 . Hong Kong children are getting fatter and less active, and parents are a big part of the problem. About $36 \%$ of them frequently or occasionally recommended their children to reduce sporting activities for studies. Children were 
physically active if their parents were. But only $18 \%$ of toddlers (ages three to six years) did an hour or more of outdoor activities on average each day. Only about half the infants did physical activities with their family at least once per week.

Sandercock, Voss, McConnell, \& Rayner, (2010), asked more than 4,000 British schoolchildren to rate how active they thought their parents were. The children then completed a cardiorespiratory fitness test. The test classified a quarter of the children as "unfit" (unable to run at a medium jogging pace of 11 kilometres per hour), and this status was strongly influenced by how active they perceived their parents (Huang et al., 2009). In addition, declines in fitness were independent of changes in BMI suggesting continued reductions in English children's habitual physical activity levels (Sandercock, Ogunleye, \& Voss, 2015).

The acquisition of physical and healthy habits skills at early childhood plays a critical role in the future lifestyle stereotype of young children. Childhood and adolescent sports participation was found to be a significant predictor of young adults' participation in sports and physical fitness activities.Active parents were those perceived by their children to do two or three sessions of physical activity per week including walking, cycling, running, playing sport, or going to a gym or an exercise class. Childhood obesity will require parents a critical role play (Huang et al., 2009; Parkins et al., 2004).

Play is essential to development because it contributes to the cognitive, physical, social, and emotional well-being of children and youth. Play also offers an ideal opportunity for parents to engage fully with their children. Report addresses a variety of factors that have reduced play, including a hurried lifestyle, changes in family structure, and increased attention to academics and enrichment activities at the expense of recess or free child-centered play (Ginsburg, 2007).

Therefore, the purpose of this study was to document the significance of the practices employed by parents that contribute to children's healthy lifestyle in Oman. Those practices encompassed the physical activity and inactivity, sedentary behavior, nutritional knowledge, and its reflection on their children at early childhood.

\section{Method}

\section{Population and sample}

Out of the 350 questionnaires distributed, only 237 responded for this study. The study sample consisted of parents who had children enrolled in kindergarten in the districts of Muscat, Al-Batinah and Al-Sharqiya.

Table 1

Mean and standard deviation of the weight, height and BMI for the sample in the study

\begin{tabular}{lllll}
\multicolumn{5}{c}{ and BMI for the sample in the study } \\
\hline \multirow{2}{*}{ Variable } & $\begin{array}{l}\text { Min } \\
\text { Value }\end{array}$ & $\begin{array}{l}\text { Max } \\
\text { Value }\end{array}$ & Mean & SD \\
& 44 & 115.0 & 71.95 & 12.95 \\
Weight & 1.49 & 1.9 & 1.64 & 0.08 \\
Height & 17.24 & 41.4 & 26.73 & 4.30 \\
BMI & 17.4 \\
\hline
\end{tabular}

$\mathrm{BMI}=\frac{\text { Mass }(\mathrm{kg})}{\text { Height }\left(\mathrm{m}^{2}\right)}$

Overweight: BMIsfrom 25 to 30

USA: over 25 Morbid obesity

Hong Kong: 25.0 - 29.9 Overweight - Moderately Obese

Japan: $\quad 25.0-30.0$ Obese (Level 1)

Singapore: $\quad 23.0$ - 27.4 Moderate risk of developing heart disease, high blood pressure, stroke, diabetes

Our record showed that $70 \%$ of the sample was healthy without any state of treatment while the rest were having diverse illness conditions range from low back pain to diabetes and blood pressure.

\section{Instrument}

The researchers built a questionnaire which dealt with the parents' practice in promoting of their children's emergent lifestyle. The questionnaire used for the study consisted of 25 items and 21 items of their involvement with their children playing activities. Reliability and content validity were sufficient to conduct and apply the survey. We piloted the questionnaire on 50 parents who participated voluntarily. Test re-test was administered within two weeks of time. The reliability of the pilot testing was 0.84 . In addition, we justify reliability on the sample participants of this study as a separate test of reliability resulted in an alpha $=0.879$ and considered to be an acceptable degree for the purposes of the current study. A group of principals in the schools at which the child attended were trained to administer the instrument during a full day workshop. The principals sent a letter about the study to each child's parents and asked them if they would agree to participate in the study. This part of the data collection lasted about three months. 


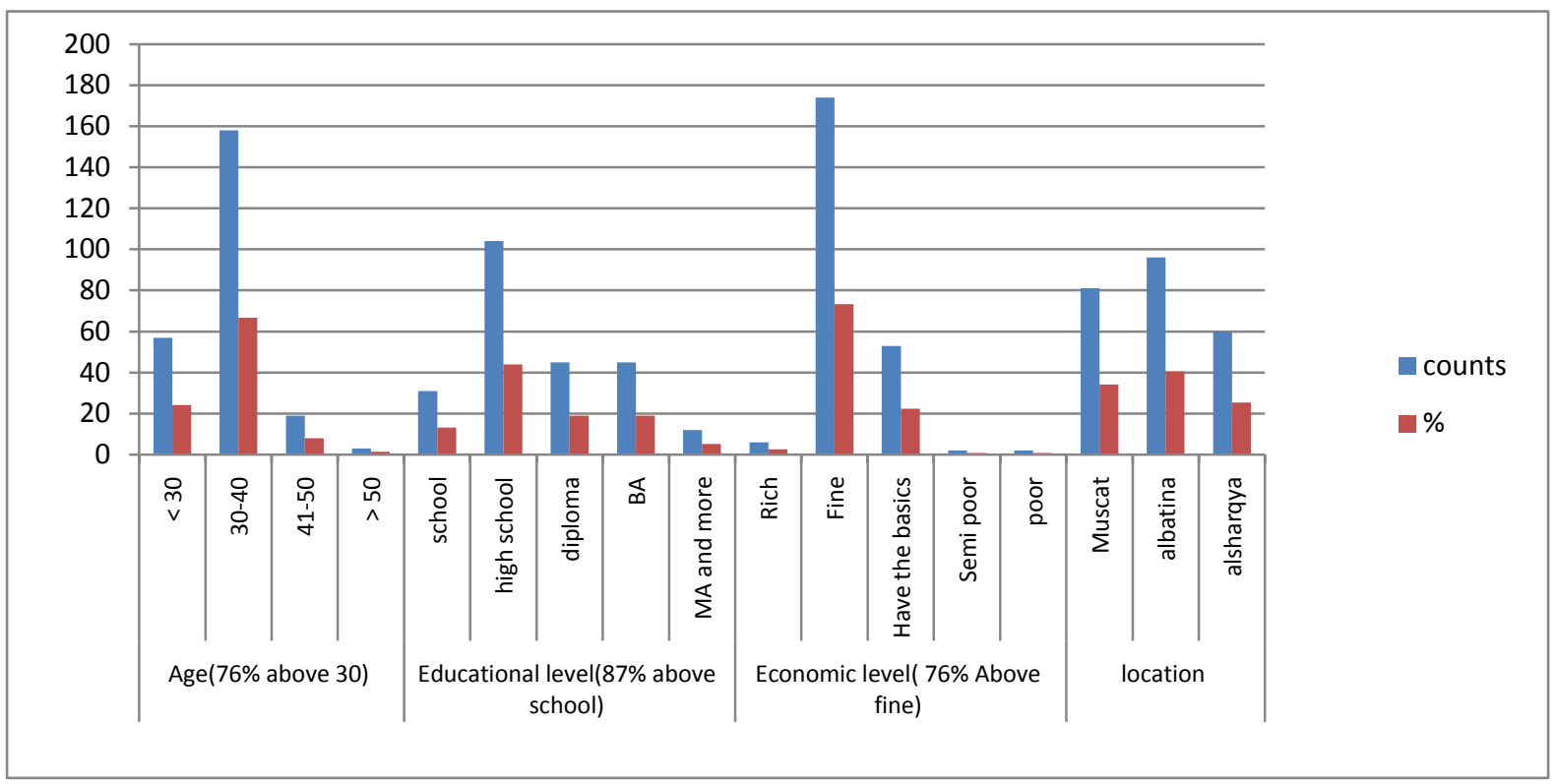

Figure 1. Demographic description of the parents' sample is depicted according to age, education, economic level and location

\section{Results}

Responses of the sample are shown according to different questions in percentages

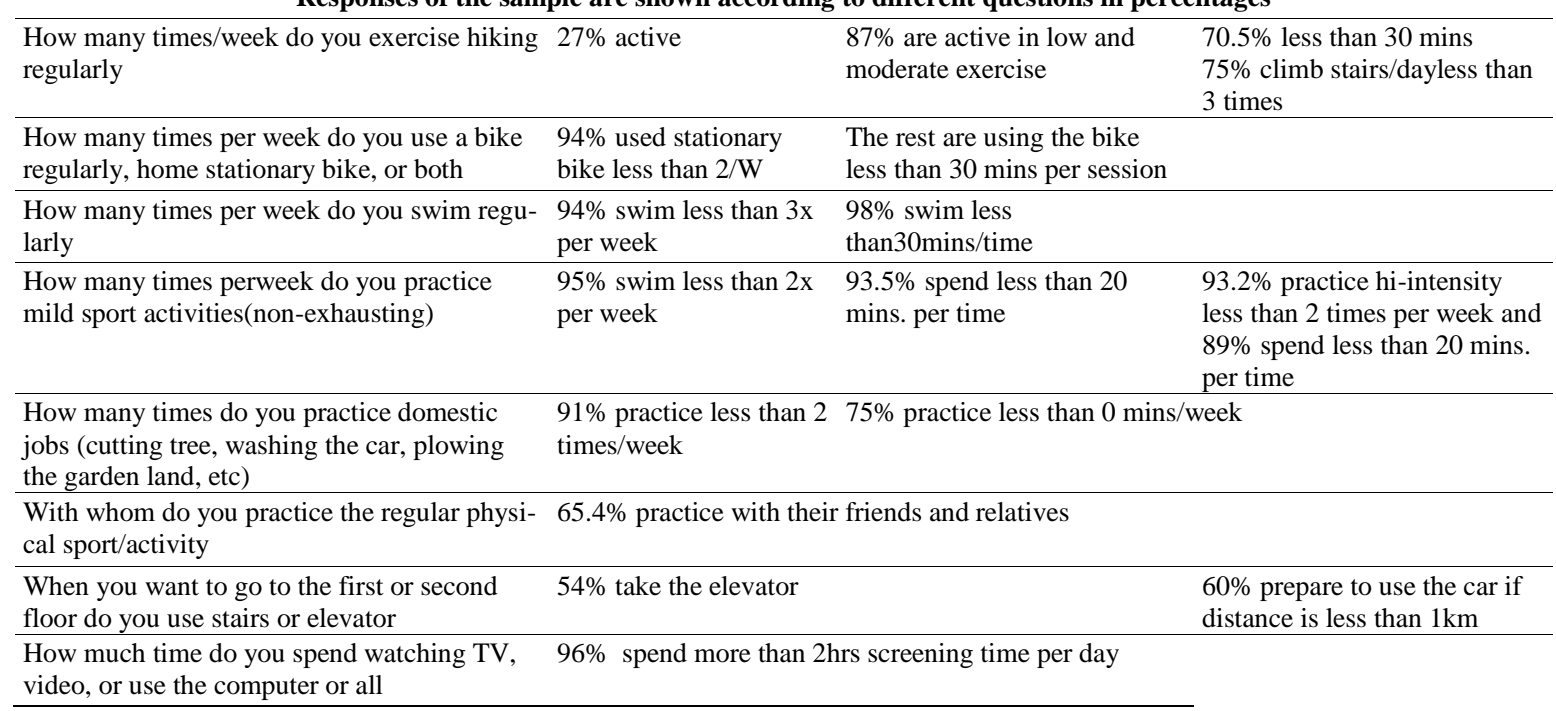

Parents were almost all having sedentary lifestyles and here not active on a daily basis as it is depicted in table 2. 


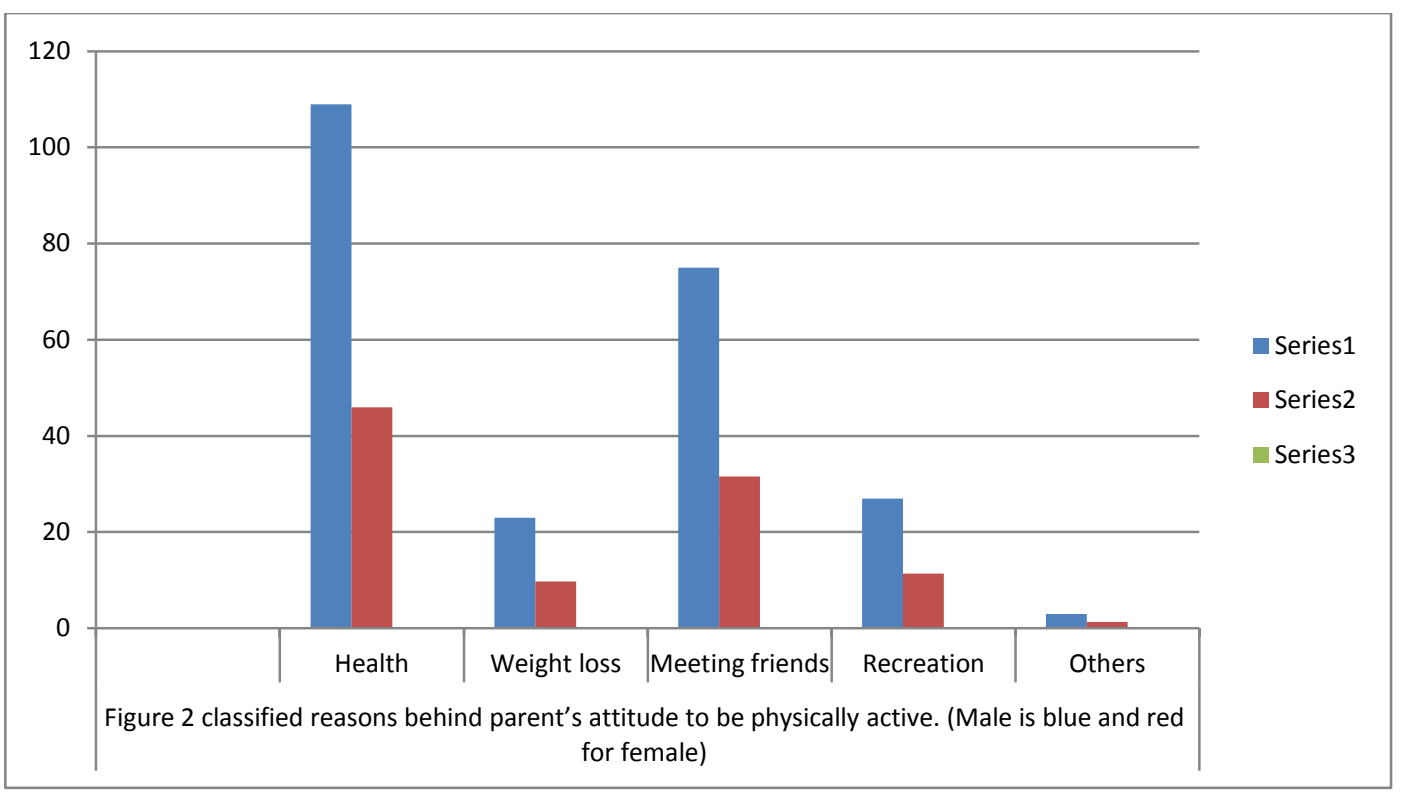

Table 3

Source of getting the nutritional information

\begin{tabular}{lrr}
\hline Category & Count & $\%$ \\
\hline Magazines & 26 & 11.0 \\
Nutritional Specialist & 12 & 5.1 \\
TV & 146 & 61.6 \\
Physician & 8 & 3.4 \\
Books & 12 & 5.1 \\
Friend & 3 & 1.3 \\
Family & 10 & 4.2 \\
Studying & 6 & 2.5 \\
Internet & 14 & 5.9 \\
\hline Total & 237 & 100.0 \\
\hline
\end{tabular}

Table 4

Frequencies and percentages for each question on sedentary trend

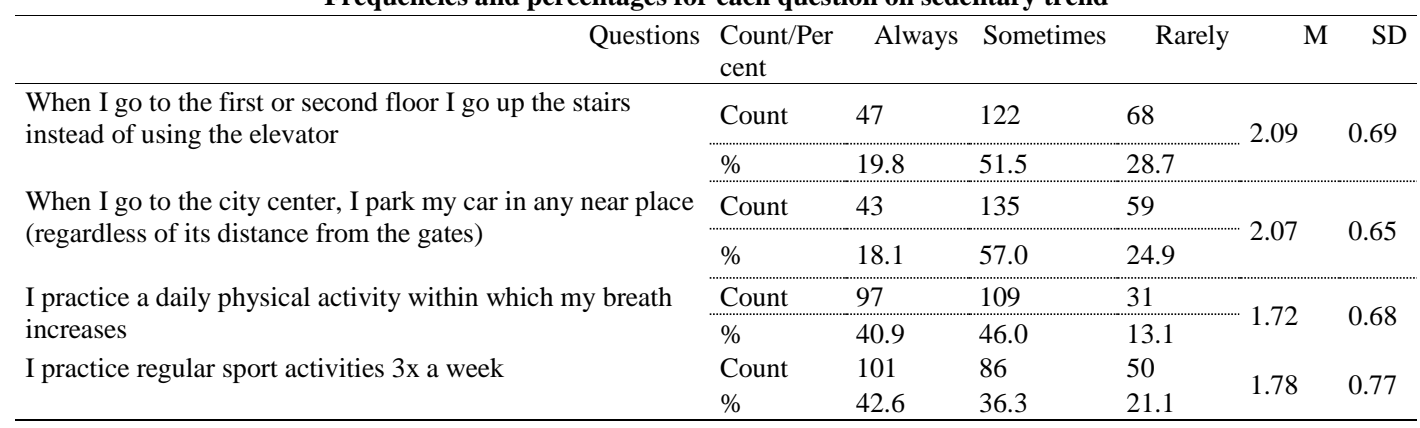

Table 5

Frequencies and percentages for each question of nutrition and health

\begin{tabular}{|c|c|c|c|c|c|c|}
\hline Questions & Count / Percent & Always & Sometimes & Rarely & M & SD \\
\hline \multirow{2}{*}{ I keep my weight within the ideal limits } & Count & 53 & 110 & 74 & \multirow{2}{*}{2.09} & \multirow{2}{*}{0.73} \\
\hline & $\%$ & 22.4 & 46.4 & 31.2 & & \\
\hline \multirow{2}{*}{ I avoid nutrients with rich calories } & Count & 53 & 122 & 62 & \multirow{2}{*}{2.04} & \multirow{2}{*}{0.70} \\
\hline & $\%$ & 22.4 & 51.5 & 26.2 & & \\
\hline \multirow{2}{*}{ I focus on nutrients rich with proteins } & Count & 28 & 134 & 75 & \multirow[b]{2}{*}{2.20} & \multirow{2}{*}{0.63} \\
\hline & $\%$ & 11.8 & 56.5 & 31.6 & & \\
\hline \multirow{2}{*}{ I choose fast foods } & Count & 137 & 93 & 7 & \multirow{2}{*}{1.45} & \multirow{2}{*}{0.55} \\
\hline & $\%$ & 57.8 & 39.2 & 3.0 & & \\
\hline \multirow{2}{*}{ I took an integrated and balanced breakfast meal } & Count & 44 & 117 & 76 & \multirow{2}{*}{2.14} & \multirow{2}{*}{0.70} \\
\hline & $\%$ & 18.6 & 49.4 & 32.1 & & \\
\hline \multirow{2}{*}{ I took at least three meals daily } & Count & 13 & 70 & 154 & \multirow{2}{*}{2.59} & \multirow{2}{*}{0.59} \\
\hline & $\%$ & 5.5 & 29.5 & 65.0 & & \\
\hline \multirow{2}{*}{$\begin{array}{l}\text { I apply the health-related nutritional information on } \\
\text { my children }\end{array}$} & Count & 10 & 101 & 126 & \multirow{2}{*}{2.49} & \multirow{2}{*}{0.58} \\
\hline & $\%$ & 4.2 & 42.6 & 53.2 & & \\
\hline
\end{tabular}


Table 6

\begin{tabular}{|c|c|c|c|c|c|c|}
\hline \multicolumn{7}{|c|}{ Frequencies and percentages for each question on parents' participation with their children } \\
\hline Questions & $\begin{array}{l}\text { Count/ } \\
\text { Percent }\end{array}$ & Always & Sometimes & Rarely & M & SD \\
\hline \multirow[t]{2}{*}{ I play with my children at home } & Count & 19 & 115 & 103 & 2.35 & \multirow{2}{*}{0.63} \\
\hline & $\%$ & 8.0 & 48.5 & 43.5 & & \\
\hline \multirow{2}{*}{$\begin{array}{l}\text { I encourage my children to practice physical activities } \\
\text { instead of playing electronic games }\end{array}$} & Count & 13 & 121 & 103 & 2.38 & \multirow{2}{*}{0.59} \\
\hline & $\%$ & 5.5 & 51.1 & 43.5 & & \\
\hline \multirow{2}{*}{$\begin{array}{l}\text { My child watch daily TV programs most of the day } \\
\text { time }\end{array}$} & Count & 62 & 137 & 38 & 1.90 & \multirow{2}{*}{0.64} \\
\hline & $\%$ & 26.2 & 57.8 & 16.0 & & \\
\hline \multirow{2}{*}{$\begin{array}{l}\text { I'm aware about my children's health because of the } \\
\text { long time he spends watching TV }\end{array}$} & Count & 19 & 62 & 156 & 2.58 & \multirow{2}{*}{0.64} \\
\hline & $\%$ & 8.0 & 26.2 & 65.8 & & \\
\hline \multirow{2}{*}{$\begin{array}{l}\text { My children scratch their eyes and shed tears because } \\
\text { of the electronic games }\end{array}$} & Count & 132 & 85 & 20 & 1.53 & \multirow{2}{*}{0.65} \\
\hline & $\%$ & 55.7 & 35.9 & 8.4 & & \\
\hline \multirow{2}{*}{$\begin{array}{l}\text { My children suffer serve exhaustion and decreased } \\
\text { concentration because of the electronic games }\end{array}$} & Count & 106 & 102 & 29 & 1.68 & \multirow{2}{*}{0.68} \\
\hline & $\%$ & 44.7 & 43.0 & 12.2 & & \\
\hline \multirow{2}{*}{$\begin{array}{l}\text { I notice that my children tend to be lazy and over- } \\
\text { weight because of the electronic games }\end{array}$} & Count & 151 & 68 & 18 & 1.44 & \multirow{2}{*}{0.63} \\
\hline & $\%$ & 63.7 & 28.7 & 7.6 & & \\
\hline \multirow{2}{*}{$\begin{array}{l}\text { I can't control orienting my children's behavior to- } \\
\text { wards physical activity nor early sleep }\end{array}$} & Count & 92 & 115 & 30 & 1.74 & \multirow{2}{*}{0.67} \\
\hline & $\%$ & 38.8 & 48.5 & 12.7 & & \\
\hline
\end{tabular}

\section{Discussion}

Omani parents are not involved in routine physical activity and their tendency to sedentary lifestyle is significant. Although $45 \%$ of Omani parents practice physical exercise for health reasons and $35 \%$ to meet friends, other responses contradict the reality of their habit andthey do not spend time playing with their children at home. Most information and facts of nutrition conception to Omani parents perceived through TVs which account of $62 \%$. This explains how much screen time they spend in front of TV.

Despite the fact that Omani parents' knowledge of health nutrition lifestyle is modest, they do not care applying health-related nutrition into their children's eating habits. Gibson, Kreichauf, Wildgruber, Voegele, Summerbell, Nixon et al. (2012)indicated that how parents might be directly or indirectly influencing their children's food preferences at home, which in turn affect energy intake. This could have a positive effect on social modelling by parents can be effective in encouraging healthier eating.Mean while, An individual's social surrounding, such as housing, facilities for education and health care, workplaces and open space for recreation and social relationships, by means of the interactions between various individuals or groups can also have a profound impact on the quality of parenting, which in turn affects a child's health development and future achievements. Inclusive social environments which provide support to parents have been shown to enhance parents' capacity to care for their children and in doing so promote better child health and development (Harding, 2003; Lansford, Antonucci, Hiroko, Keiko, \& Takahashi, 2005).

On the other hand, most Omani parents do not encourage their children to practice physical activities instead of playing electronic games. High percentages of Omani parents are not aware about their children's health because of the long time they spend watching TV. Most importantly, Omani parents can't control orienting their children's behaviour toward physical activity nor early sleep. Kilani et al. (2013) provided evidence of the high prevalence of sedentary behaviors and low levels of PA, especially among females. Sedentary lifestyles were also common among the adult Omani women studied. Lack of physical activity and increased sedentary behavior is known to increase the risk of metabolic syndrome and obesity (Al-Habsi \& Kilani, 2015). Modern life routines had introduced several alterations to the Omani community lifestyle. These alterations of the lifestyle resulted in less chances of regular PA. The resultant inactive sedentary lifestyle had serious impacts on the health of the society demonstrated clearly as alterations of the body composition and emerging of 
chronic diseases (Kilani et al., 2014). The sedentary lifestyle in the Omani society has been associated with an increase in noncommunicable diseases (NCDs) (Kilani, 2007; Kilani et al., 2013). The crude prevalence of overweight and obesity (body mass index $>25$ $\mathrm{kg} / \mathrm{m}^{2}$ ) among Omani adults was estimated to be $47.9 \%$ and the crude prevalence of central obesity was $49.3 \%$ (18). Both obesity and central obesity increased the odds of having diabetes, hypertension and hypercholesteremia. (Al-Riyami \& Afifi, 2003). Our surveillance of the parents did not differ from most population of Omani society except in their attitude towards physical activity. Encouraging a physically active lifestyle for children may be beyond what Omani parents think. Parents can start by suggesting several options that are available through local park districts, schools, and community programs and all are easier than parents think. The discrepancy between parents in our study indicating a good level of attitudes towards physical activity and to promote healthy lifestyle behaviors but having less practicality that would actually be able to endorse change.

\section{Conclusion}

Research on parents' role to literacy of healthy lifestyles relevant to policy makers, educators, and practitioners who seek to promote the positive attitudes toward young childrens healthy lifestyle. Intervention, training courses, workshops, and seminars for the parents with low educational levels should be conducted in order to create an awareness of the importance of early healthy behavior. These are tools to be carried with parents and inculcate their children as early as possible so they can change their lifestyle to better off must be cultured.

Further research using testing and measurement is needed to correlate:

1. Physical fitness levels and educational achievement

2. Risk factors in both early childhood with their parents

Additional investigations in rural areas and other locales and districts with different social and economic levels should be involved. The role of technology games at home and in kindergarten; child's lifestyle, parents' knowledge of child's behavioral development, and the availability of outside-related resources avail- able to families should be investigated in Oman.

\section{References}

Al-Habsi, A., \& Kilani, H. (2015). Lifestyle of Adult Omani Women: A Cross Sectional Study. Sultan Qaboos University Medical Journal, 15, 2, 241-249.

Al-Qaryouti, I., \& Kilani, H. (2015). Role of Omani Parents: Fostering Emergent Literacy Skills. Education 3-13, 43, 3, 336-348, http://dx.doi.org/10.1080/03004279.2013.8152 48.

Al-Riyami, A., \& Afifi, M. (2003). Prevalence and correlates of obesity and central obesity among Omani adults. Saudi Medical Journal, 24, 641-646.

American Heart Association. (2010).Students' physical fitness associated with academic achievement; organized physical activity. ScienceDai-

ly. $<w w w . s c i e n c e d a i l y . c o m / r e l e a s e s / 2010$ /03/100302185522.htm>.

Brophy, S., Rees, A., Knox, G., Baker, J. \& Thomas, N. (2012). Child Fitness and Father's BMI Are Important Factors in Childhood Obesity: A School Based CrossSectional Study. PLoS ONE 7(5): e36597. doi:10.1371/journal Pone. 0036597

Gibson EL, Kreichauf S, Wildgruber A, Voegele C, Summerbell CD, Nixon C, Moore H, Douthwaite W, Manios Y, ToyBox-Study G (2012) A narrative review of psychological and educational strategies applied to young children's eating behaviours aimed at reducing obesity risk. Obes Rev, 13,85-95

Ginsburg, K. (2007). The importance of play in promoting healthy child development and maintaining strong parent-child bonds. Pediatrics, $\quad 119,182-191$. doi:10.1542/peds .2006-2697

Harding, D. (2003). Counterfactual models of neighborhood effects: The effect of neighborhood poverty on dropping out and teenage pregnancy. Am J Sociol., 109(3): 676-719.

Huang, J., Sallis, J., \& Patrick, K. (2009). The role of primary care in promoting children's physical activity Review. Br J Sports Med,43,19-21 doi:10.1136/bjsm.2008.055277. 
Lansford, J., Antonucci, T., Hiroko, A., Keiko, T., \& Takahashi, K. ( 2005). A quantitative and qualitative approach to social relationships and well-being in the United States and Japan. Journal of Comparative Family Studies, 36(1), 1-22.

LCSD. (2013). Parents play important role in kids' fitness. South China Morning Post.http:/ / www.scmp.com/lifestyle/fam ily-education/article/1199489/ parentsplay-important-role-kids-fitness.

Kilani, H. (2007). Significance of exercise and nutrition on bone health. In proceedings: Third Arab Nutrition Conference, Abu Dhabi, United Arab Emeritus.

Kilani, H., Alhazzaa, H., Waly, M., \& Musaiger, A. (2013). Lifestyle Habits: Diet, Physical Activity and Sleep Duration among Omani Adolescents. Sultan Qaboos University Medical Journal, 13, 510-519.

Kilani, H. (2014). Fetal-Neonatal Basis Lifestyle of the Adult Metabolic Syndrome (OBESITY) and exercise. International Fight Obesity Symposium (5/1/2014 @ Golden tulip Hotel)

Kilani,H.\& Alerjan,J.(2001). Correlation between the level of fitness and learning achievement in High School. 1st Educational Activity Conference, Proceedings.UAE: Dubai.

Kilani, H. (2015). Cardiovascular Diseases Risk, Energy Expenditure, and Health Fitness. Canad J Clin Nutr, 3, 2,1-4. DOI:http://dx.doi.org/10.14206/canad.j.c lin.nutr.2015.02.01

Lindsay, A.,Sussner, K., Kim, J\& Gortmaker, S.(2006). The role of parents in preventing childhood obesity. Future Child, 16, 1,16986.

Mehana, M. \& Kilani, H. (2010). Enhancing Physical Education in Omani Basic Education Curriculum: Rationale and Implications. International Journal for CrossDisciplinary Subjects in Education (IJCDSE), 1, 2, 1-6.

Perkins, D., Jacobs J., Barber, B., \& Eccles J. (2004). Childhood and adolescent sports participation as predictors of participation in sports and physical fitness activities during young adulthood. Youth $\mathcal{E}$ Soc, 35, 495-520. 10.1177/0044118X03261619.

Sandercock, G., Voss, C., McConnell, D. \& Rayner, P. (2009). Declines in aerobic fitness are largely independent of body mass index in affluent English schoolchildren. Arch Dis Child, 1, 46-7. doi: 10.1136/adc.2009.162107.

Sandercock, G., Ogunleye, A., \& Voss, C.( 2015). Six-year changes in body mass index and cardiorespiratory fitness of English schoolchildren from an affluent area. Int J Obes, 1-4. doi:10.1038/ijo.2015.105.

Tremblay, S., Esliger, W., Tremblay, A., \& Colley, R. (2007) Incidental movement, lifestyle-embedded activity and sleep: new frontiers in physical activity assessment. Can. J. Public Health, 98: S208-S217 a Medline.

Tremblay, M., Wolfson, M., \& Gorber, C. (2007) Canadian Health Measures Survey: rationale, background and overview. Health Rep, 18, 7-20.

Voss, C., \& Sandercock, G. (2010). Aerobic fitness and mode of travel to school in Englis h schoolchildren. Medical Science Sports Exercise, 42, 2, 281-287.

VaLippevelde, W., Verloigne, M., Bourdeaudh uij, I., Brug, J., Bjelland, M., Lien, N.

\& Maes, L. (2012). Does parental involvement make a difference in schoolbased nutrition and physical activity interventions? A systematic review of randomized controlled trials. Int J Public Health. 57(4),673-876. doi: 10.1007/s00038012-0335-3.

Welk, G ., Wood, K, \& Morss, G.( 2003). Parental influences on physical activity in children: an exploration of potential mechanisms. Pediatr Exerc Sci , 15, 19-33. 